\title{
Car Fuel Economy Simulation Forecast Method Based on CVT Efficiencies Measured from Bench Test
}

\author{
Yu-Long Lei ${ }^{1}$, Yu-Zhe Jia ${ }^{2}$, Yao Fu ${ }^{1 *}$, Ke Liu$^{1}$, Ying Zhang ${ }^{3}$ and Zhen-Jie Liu ${ }^{4}$
}

\begin{abstract}
Researchers face difficulties in studying the effects of driveline efficiency on car fuel economy via bench and road tests because of long working periods, high costs, and heavy workloads. To simplify the study process and shorten test cycles, a car fuel economy simulation forecast method for combining computer simulation forecasting with bench tests is proposed. Taking a continuously variable transmission (CVT) as the research object, a transmission efficiency model based on a bench test is constructed. An optimal economic variogram based on the original CVT variogram, the boundary conditions of vehicle performance, the road conditions and the driving behavior of the driver is generated in the Gear Shift Program (GSP)-Generation module in AVL Cruise. And on this basis a driveline simulation model that can calculate the fuel consumption based on the driveline data of a test car is built. The model is used to forecast fuel consumption and calculate real-time CVT efficiency under different conditions. Contrastive analyses on simulation results and real car drum test results are made. The largest error between simulation results and drum test results in driving cycles is $4.099 \%$, which is $5.449 \%$ under constant velocity condition in driver control mode and $4.2 \%$ under constant velocity condition in automatic cruise mode. The results confirm the feasibility of the method and the good performance of the driveline simulation model in accurately forecasting fuel consumption. The method can efficiently investigate the effects of driveline efficiency on car fuel economy. Moreover, this research provides instruction for accurately forecasting fuel economy as well as references for studies on the effects of drivelines on car fuel economy.
\end{abstract}

Keywords: Fuel economy, CVT efficiency, Simulation forecast, Driveline

\section{Introduction}

Driveline efficiency can significantly affect car fuel economy, and studying this relationship through bench and road tests requires long working periods, high costs, and heavy workloads. Such tests can also lead to certain blindness for the determination of vehicle and various assembly schemes, the selection of structural parameters and the matching of driveline parameters with an engine, all of which can affect the creation of a better matching program, result in an unsatisfactory product performance, and wastage of resources [1]. Therefore, various

\footnotetext{
*Correspondence: fu_yao@jlu.edu.cn

${ }^{1}$ State Key Laboratory of Automotive Simulation and Control, Jilin University, Changchun 130022, China

Full list of author information is available at the end of the article
}

computer simulation forecasting methods assisted by bench tests have been widely adopted to optimize driveline matching and study transmission efficiency. Such methods can improve design quality, shorten the development cycle, and reduce costs [2]. Numerous studies on the efficiency of CVT and gearbox have been conducted through bench tests in China and abroad. Akehurst et al. [3-5] used bench tests to study torque losses in a metal belt CVT, which were caused by the relative sliding motion between belt segments and bands. They then forecasted and studied torque losses between belt segments and bands caused by the bending and deformation of the pulley based on experimental observations of pulley deflections. Furthermore, they studied the sliding speed of belt segments relative to the primary and secondary pulleys and its effects on torque loss, after which 
they proposed a model for the effects. They validated their proposed model using a number of experimental data. Meanwhile, various transmission power losses of CVT have been analyzed, and the transmission efficiencies of metal belts have been measured through bench tests [6]. However, the effects of CVT efficiency on car fuel economy have not yet been studied through real car tests. Huang et al. [7] conducted a CVT efficiency bench test using an electronically controlled gasoline engine as the power source, in which ratio, torque, and torque transmission ranges with high efficiency were measured. However, they did not validate the results using a real car test. In addition, researchers have investigated the influences of gear precision, bearing fit quality, and gear oil in the gearbox on transmission efficiency. Wang et al. [8] selected manual transmission as the research object to determine the influence of different gear precisions on transmission drive efficiency under various working conditions through bench tests. The results showed that a high-precision gear with a grinding process could evidently improve transmission drive efficiency. Gear precision mainly influences mesh precision and transmission dynamic stability. Considerable work has been done to analyze the influence of different types of gear oil on transmission efficiency under various working conditions through bench tests [9-11]. Similarly, Zhu et al. [12] studied the power loss of CVTs, including torque loss and speed loss, based on the transmission mechanism of CVTs, and experiments on CVT efficiency were conducted on a specific CVT test bench. Furthermore, they provided optimal structural parameters to serve as references for designing and tuning CVTs.

Numerous studies on CVT efficiency have been conducted using computer simulation forecasting. Luo et al. [13] developed an optimum economic control strategy considering both engine and CVT efficiencies to compensate for the deficiencies of traditional optimum economic matching strategies, and this method was validated through simulations and bench tests. Cai [14] built one loss model for the hydraulic pump and the metal belt and another model for CVT pressure and ratio based on experimental data. In addition, driving cycle simulations based on these models and real car tests have been conducted to validate the models and analyze the effects of hydraulic pump and metal belt losses. Wang [15] developed efficiency models of driveline components based on the analytical method. Afterward, contrastive simulations of driving cycles and constant velocity conditions based on fixed transmission efficiencies and efficiency models was conducted. The simulation results showed that the simulation of fuel consumption based on the efficiency models was close to the actual results, which were measured in real car tests. However, difficulties in high-precision analytical models and a substantial number of calculations have been encountered in using these efficiency models. Yan et al. [16] studied the sensitivity of the effect of driveline efficiency on the car fuel economy of a step transmission car through fuel economy simulation programs. Huang [17] proposed a forecast program based on the establishment of engine universal characteristic forecast models and the calculation methods for fuel economy, this program was subsequently validated via real bus tests. A fuel economy forecast method was also proposed based on the test procedure established by the United States Federal Environmental Protection Agency; this method was validated through simulation analyses [18].

To facilitate data development and reference matching, simplify calculation models, and ensure the accuracy of simulation models without performing a real car test, the transmission efficiency data of various components and losses of driveline measured through bench tests are used as assistant data and inputted into computer simulation software to forecast car fuel economy. In this research, a method for combining computer simulation forecast with CVT efficiency bench test is proposed based on the study results above. A driveline simulation model based on CVT efficiencies is subsequently built to forecast car fuel consumption. In Section 2, the driveline simulation model considering the fuel consumption calculation and the input interface of the CVT efficiency model is modeled. Then in Section 3, the CVT efficiency is tested through bench tests, and a function of the piecewise programming lookup is proposed, CVT efficiency model based on this function is connected with the input interface of the driveline simulation model. Driveline simulation system structure is presented in Section 4, and the optimal economic variogram assisting in improving torque converter (TC) efficiency and transmission efficiency [19] is generated to achieve ratio control. Test cycles and conditions are presented in Section 5, the simulation model and the real car drum tests in Section 6 are run to follow the conditions. Real car drum tests, contrastive analysis and discussions of simulation and drum test results are presented in Section 6, followed by conclusions. The results of the contrastive fuel consumption simulations and the real car drum tests show that the car driveline simulation model based on CVT efficiencies measured from a bench test and the driveline data of a test car provides good accuracy in forecasting values, thereby providing effective references for future studies on the effects of driveline on car fuel economy. 


\section{Car Driveline Modeling}

In this study, a simplified model for a driveline equipped with a CVT is built using the lumped mass method [20], which is based on a real CVT car (Figure 1).

The following assumptions are made in this model.

(1) The dynamic response process of the engine output torque is not considered when the throttle opening is changed transiently.

(2) The torsional stiffness and viscous damping of the driveline are not considered.

(3) The dynamic characteristic effects of the CVT hydraulic actuators are not considered, and the relationship between CVT ratio and ratio change rate is described using a simple integral. The effects of lockup clutch oil charge and discharge characteristics on the locking and unlocking processes are disregarded. Moreover, the effect of temperature on transmission efficiency is also not considered.

\subsection{Engine Modeling}

The engine model is built using the interpolation lookup method based on data measured through engine bench tests. Engine output torque and power are expressed as $T_{\mathrm{e}}$ $(\mathrm{N} \cdot \mathrm{m})$ and $P_{\mathrm{e}}(\mathrm{kW})$, respectively.

$$
\begin{aligned}
& T_{\mathrm{e}}=T_{e}\left(\alpha, n_{\mathrm{e}}\right), \\
& P_{\mathrm{e}}=P_{\mathrm{e}}\left(\alpha, n_{\mathrm{e}}\right),
\end{aligned}
$$

where $\alpha$ is the throttle opening (\%), $n_{\mathrm{e}}$ is the engine output speed $(\mathrm{r} / \mathrm{min})$.

The engine model considers engine braking torque, which is expressed as $T_{M}(\mathrm{~N} \cdot \mathrm{m})$ :

$$
T_{\mathrm{M}}=T_{\mathrm{M}}\left(n_{\mathrm{e}}\right) \text {. }
$$

Engine speed $n_{\mathrm{e}}(\mathrm{r} / \mathrm{min})$ is calculated using the following equation:

$$
n_{\mathrm{e}}=\frac{u_{\mathrm{a}} i_{0} i}{0.377 r_{\mathrm{w}} i_{\mathrm{TC}}},
$$

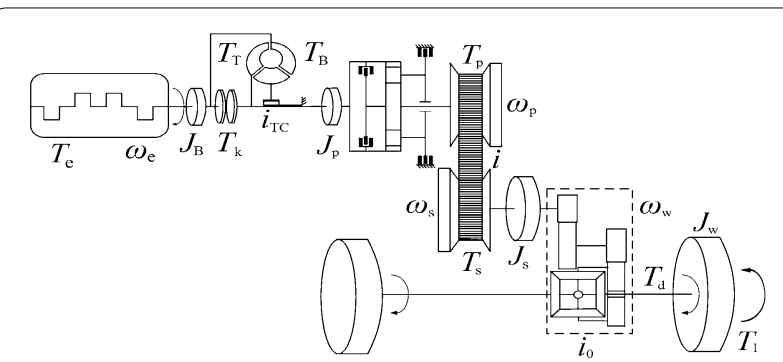

Figure 1 Simplified model of the driveline with a CVT where $u_{\mathrm{a}}$ is the vehicle speed $(\mathrm{km} / \mathrm{h}), i_{0}$ is the Total final drive ratio (product of intermediate ratio and final drive ratio), $i$ is the CVT speed ratio, $r_{\mathrm{w}}$ is the wheel rolling radius $(\mathrm{m}), i_{\mathrm{TC}}$ is the $\mathrm{TC}$ speed ratio.

Engine fuel consumption per unit time $(\mathrm{L} / \mathrm{h})$ is obtained from the lookup table based on engine output speed $n_{e}$ and output torque $T_{\mathrm{e}}$, which is expressed as $Q_{\mathrm{t}}(\mathrm{L} / \mathrm{h})$ :

$$
Q_{\mathrm{t}}=Q_{\mathrm{t}}\left(n_{\mathrm{e}}, T_{\mathrm{e}}\right) \text {. }
$$

Engine cumulative fuel consumption (L) is expressed as $Q(\mathrm{~L})$ :

$$
Q=\int Q_{\mathrm{t}} \mathrm{d} t
$$

Fuel consumption per hundred kilometers $Q_{\mathrm{s}}(\mathrm{L} / 100 \mathrm{~km})$ is calculated using

$$
Q_{\mathrm{s}}=\frac{100 \int Q_{\mathrm{t}} \mathrm{d} t}{\int u_{\mathrm{a}} \mathrm{d} t} .
$$

Transient and cumulative fuel consumption can be worked out based on the Eqs. (5)-(7).

\subsection{Car Driveline Modeling}

\subsubsection{TC Equipped with a Lockup Clutch Modeling}

CVT is connected with a planetary gear set, which is used to make a switch from the drive gear to the reverse gear. In this study, only the drive gear is considered; thus, the drive gear clutch is engaged, whereas the reverse gear clutch is released. The planetary gear set rotates as a whole with a ratio of 1.0. The planetary gear set is considered as a component of the CVT input terminal. This terminal is connected with the TC, which is connected with the engine output terminal and is also equipped with a lockup clutch called torque converter clutch (TCC). The relationship between TC pump torque and engine output torque is expressed as [21]

$$
J_{\mathrm{B}} \dot{\omega}_{\mathrm{e}}=T_{\mathrm{e}}-T_{\text {loss }}-T_{\mathrm{B}}-T_{\mathrm{k}},
$$

where $J_{\mathrm{B}}$ is the inertia moment of engine flywheel, pump, and primary part of lockup clutch, $\left(\mathrm{kg} \cdot \mathrm{m}^{2}\right), \omega_{\mathrm{e}}$ is the engine output angular speed $(\mathrm{rad} / \mathrm{s}), T_{\text {loss }}$ is the torque losses of other components equivalent to the output terminal of the engine, except engine-CVT box driveline, $(\mathrm{N} \cdot \mathrm{m}), T_{\mathrm{B}}$ is the pump torque $(\mathrm{N} \cdot \mathrm{m}), T_{\mathrm{k}}$ is the TCC torque, $(\mathrm{N} \cdot \mathrm{m})$.

The turbine-to-pump speed ratio is expressed as $i_{\mathrm{TC}}$ :

$$
i_{\mathrm{TC}}=\frac{\omega_{\mathrm{p}}}{\omega_{\mathrm{e}}},
$$


where $\omega_{\mathrm{p}}$ is the angular speed of CVT primary pulley $(\mathrm{rad} / \mathrm{s})$.

The turbine-to-pump torque ratio is expressed as $K$ :

$$
K=\frac{T_{\mathrm{T}}}{T_{\mathrm{B}}},
$$

where $T_{\mathrm{T}}$ is the turbine torque $(\mathrm{N} \cdot \mathrm{m})$.

The efficiency of the TC equipped with a lockup clutch is expressed as $\eta_{\mathrm{TC}}$ [22]:

$$
\eta_{\mathrm{TC}}=\frac{\left[K\left(T_{\mathrm{e}}-T_{\mathrm{loss}}-T_{\mathrm{k}}\right)+T_{\mathrm{k}}\right] i_{\mathrm{TC}}}{T_{\mathrm{e}}-T_{\mathrm{loss}}} .
$$

The relationship between torque ratio and speed ratio is expressed as

$$
K=K\left(i_{\mathrm{TC}}\right) .
$$

The relationship between TC turbine and CVT input shaft is expressed as [21]

$$
\omega_{\mathrm{T}}=\omega_{\mathrm{p}}
$$

where $\omega_{\mathrm{T}}$ is the turbine angular speed, $\mathrm{rad} / \mathrm{s}$.

$$
J_{\mathrm{p}} \dot{\omega}_{\mathrm{p}}=T_{\mathrm{T}}+T_{\mathrm{k}}-T_{\mathrm{p}},
$$

where $J_{\mathrm{p}}$ is the inertia moment of CVT input terminal (including CVT primary pulley, planetary gear set, turbine, and the secondary component of TCC) $\left(\mathrm{kg} \cdot \mathrm{m}^{2}\right)$, $T_{\mathrm{p}}$ is the primary pulley torque acted on by metal band $(\mathrm{N} \cdot \mathrm{m})$.

In practical calculation, the slipping of TCC is not considered, and TCC is directly controlled by the locking and unlocking signals.

\subsubsection{Dynamic CVT Modeling Based on Efficiency [23]}

CVT speed ratio is expressed as

$$
i=\frac{\omega_{\mathrm{p}}}{\omega_{\mathrm{s}}}=\frac{\mathrm{T}_{\mathrm{s}}}{\mathrm{T}_{\mathrm{p}} \eta}
$$

where $\omega_{\mathrm{s}}$ is the angular speed of CVT secondary pulley $(\mathrm{rad} / \mathrm{s}), \mathrm{T}_{\mathrm{s}}$ is the secondary pulley torque acted on by metal band $(\mathrm{N} \cdot \mathrm{m}), \eta$ is the CVT efficiency (total efficiency of CVT mechanism, intermediate gears, final drive, differential, and drive shaft), which is calculated based on torque losses of CVT measured from a bench test in the subsequent discussion, and a input interface of the CVT efficiency model is reserved in this driveline simulation model.

CVT ratio range is expressed as

$$
i_{\min }<i<i_{\max }
$$

where $i_{\min }$ is the CVT minimum ratio, $i_{\max }$ is the CVT maximum ratio.

The dynamic model for CVT is established based on Figure 1 and is given by

$$
J_{\mathrm{p}} \dot{\omega}_{\mathrm{p}}=T_{\text {in }}-T_{\mathrm{p}} .
$$

$T_{\text {in }}$ is expressed as the following based on Eq. (14):

$$
T_{\text {in }}=T_{\mathrm{T}}+T_{k},
$$

where $T_{\text {in }}$ is the CVT input torque $(\mathrm{N} \cdot \mathrm{m})$.

$$
J_{\mathrm{s}} \dot{\omega}_{\mathrm{s}}=T_{\mathrm{s}}-\frac{T_{\mathrm{d}}}{i_{0}}
$$

where $J_{\mathrm{s}}$ is the Inertia moment of the CVT output terminal (including CVT secondary pulley, intermediate gears, final drive, and drive shaft) $\left(\mathrm{kg} \cdot \mathrm{m}^{2}\right) ; T_{\mathrm{d}}$ is the drive torque of the car $(\mathrm{N} \cdot \mathrm{m})$.

$$
\dot{\omega}_{\mathrm{p}}=\frac{\mathrm{d} i}{\mathrm{~d} t} \omega_{\mathrm{s}}+\mathrm{i} \dot{\omega}_{\mathrm{s}}
$$

The relationship among Eqs. (15), (17), (19), and (20) can be derived using

$$
\begin{aligned}
& J_{\mathrm{p}} i^{2} \dot{\omega}_{\mathrm{s}}+\frac{J_{\mathrm{s}} \dot{\omega}_{\mathrm{s}}}{\eta}=i T_{\mathrm{in}}-J_{\mathrm{p}} \frac{\mathrm{d} i}{\mathrm{~d} t} \omega_{\mathrm{s}} i-\frac{T_{\mathrm{d}}}{\eta i_{0}}, \\
& T_{\text {out }}=\frac{T_{\mathrm{d}}}{i_{0}},
\end{aligned}
$$

where $T_{\text {out }}$ is the output torque of secondary pulley $(\mathrm{N} \cdot \mathrm{m})$.

\subsubsection{Modeling of Torque Acting on the Drive Wheel}

Without considering corners and tire sliding, the relationship between the drive torque acting on the drive wheels and car resistance torque is expressed as

$$
\begin{aligned}
& J_{\mathrm{a}} \dot{\omega}_{\mathrm{w}}=T_{\mathrm{d}}-\left(T_{\mathrm{l}}-F_{\mathrm{j}} r_{\mathrm{w}}\right), \\
& J_{\mathrm{a}}=\frac{W}{g} r_{\mathrm{w}}^{2}+\sum J_{\mathrm{w}},
\end{aligned}
$$

where $J_{\mathrm{a}}$ is the inertia moments of car body and wheels equivalent to drive shaft $\left(\mathrm{kg} \cdot \mathrm{m}^{2}\right), \omega_{\mathrm{w}}$ is the drive wheel angular speed $(\mathrm{rad} / \mathrm{s}), T_{1}$ is the outside resistance torque acting on the car (including rolling resistance torque, ramp resistance torque, acceleration resistance torque, and air resistance torque) (N.m), $F_{\mathrm{j}}$ is the acceleration resistance $(\mathrm{N}), W$ is the normal load on wheels $(\mathrm{N}), g$ is 
the gravity acceleration, $g=9.8 \mathrm{~m} / \mathrm{s}^{2}, J_{\mathrm{wh}}$ is the inertia moments of one wheel $\left(\mathrm{kg} \cdot \mathrm{m}^{2}\right)$.

The relationship between the outside resistance torque and outside resistance is expressed using the equation

$$
T_{1}=\left(F_{\mathrm{j}}+F_{\mathrm{f}}\right) r_{\mathrm{w}}+\left(F_{\mathrm{w}}+F_{\mathrm{i}}\right)\left(l_{c}-r_{\mathrm{w}}\right),
$$

where $F_{\mathrm{f}}$ is the rolling resistance $(\mathrm{N}), F_{\mathrm{w}}$ is the air resistance $(\mathrm{N}), F_{\mathrm{i}}$ is the ramp resistance $(\mathrm{N}), l_{c}$ is the height of car centroid (m).

\subsection{Driving Resistances Modeling [24]}

\subsubsection{Rolling Resistance Modeling}

Rolling resistance is expressed as $F_{\mathrm{f}}$

$$
F_{\mathrm{f}}=W f \cos \beta,
$$

where $f$ is the rolling resistance coefficient; $\beta$ is the ramp angle. In this study, the rolling resistance coefficient is fitted and calculated based on the drive resistance of the drum test. This coefficient is expressed as

$$
f=4 \times 10^{-5} u_{\mathrm{a}}^{2}+2 \times 10^{-16} u_{\mathrm{a}}+0.8753 .
$$

\subsubsection{Air Resistance Modeling}

Without considering winds, air resistance acting on a car is expressed as $F_{\mathrm{W}}(\mathrm{N})$ :

$$
F_{\mathrm{W}}=\frac{C_{\mathrm{D}} A u_{\mathrm{a}}^{2}}{21.15},
$$

where $C_{\mathrm{D}}$ is the air resistance coefficient, $A$ is the frontal area.

\subsubsection{Ramp Resistance Modeling}

Ramp resistance, which is defined as the component force of gravity along the ramp when a car is running uphill, is expressed as $F_{\mathrm{i}}(\mathrm{N})$ :

$$
F_{\mathrm{i}}=G \sin \beta .
$$

When ramp angle is small, ramp resistance can be approximately calculated using the equation:

$$
F_{\mathrm{i}} \approx G \tan \beta=G i_{\mathrm{R}},
$$

where $G$ is the gravity acting on car $(\mathrm{N}), i_{\mathrm{R}}$ is the road gradient (\%).

\subsubsection{Acceleration Resistance Modeling}

Acceleration resistance is defined as the mass inertia force of a car that should be overcome when the car is accelerating. The acceleration resistance of a car equipped with a CVT box is expressed as

$$
F_{\mathrm{j}}=\delta_{1} \frac{\mathrm{d} i_{\mathrm{TC}}}{\mathrm{d} t}+\delta_{2} \frac{\mathrm{d} u}{\mathrm{~d} t}+\delta_{3} \frac{\mathrm{d} i}{\mathrm{~d} t},
$$

where

$$
\begin{gathered}
\delta_{1}=m+\frac{\sum J_{\mathrm{wh}}}{r_{w}^{2}}+\frac{J_{\mathrm{B}} i^{2} i_{0}^{2}}{r_{\mathrm{w}}^{2} i_{\mathrm{TC}}}+\frac{J_{\mathrm{p}} i^{2} i_{0}^{2}}{r_{\mathrm{w}}^{2}}+\frac{J_{\mathrm{s}} i_{0}^{2}}{r_{\mathrm{w}}^{2}} \\
-\frac{\left(J_{\mathrm{B}} K+i_{\mathrm{TC}} J_{\mathrm{p}}\right)\left(1-\eta_{\mathrm{T}}\right) i^{2} i_{0}^{2}}{r_{\mathrm{w}}^{2} i_{\mathrm{TC}}}, \\
\delta_{2}=\frac{J_{\mathrm{B}} i^{2} i_{0}^{2} u}{r_{\mathrm{w}}^{2} i_{\mathrm{TC}}^{3}}-\frac{(32)}{\left.r_{\mathrm{B}} K+i_{\mathrm{TC}} i_{\mathrm{p}}\right)\left(1-\eta_{\mathrm{T}}\right) i^{2} i_{0}^{2} u}-\frac{J_{\mathrm{p}} i^{2} i_{0}^{2}\left(1-\eta_{\mathrm{T}}\right)}{r_{\mathrm{w}} i_{\mathrm{TC}}}, \\
\delta_{3}=\frac{J_{\mathrm{B}} i i_{0}^{2} u}{r_{\mathrm{w}}^{2} i_{\mathrm{TC}}^{2}}+\frac{J_{\mathrm{p}} i i_{0}^{2} u}{r_{\mathrm{w}}^{2}}-\frac{\left(J_{B} K+i_{\mathrm{TC}} J_{\mathrm{p}}\right)\left(1-\eta_{\mathrm{T}}\right) i i_{0}^{2} u}{r_{\mathrm{w}}^{2} i_{\mathrm{TC}}},
\end{gathered}
$$

where $\eta_{\mathrm{T}}$ is the driveline efficiency, $\eta_{\mathrm{T}}=\eta, u$ is the vehicle speed $(\mathrm{m} / \mathrm{s})$.

However, TCC is locked up at $20 \mathrm{~km} / \mathrm{h}$ and unlocked at $15 \mathrm{~km} / \mathrm{h}$ in practical application, which indicates that the period during which TC works in a hydraulic drive mode is short. Hence, we only consider the period of a mechanical drive mode in the calculation to simplify the model, and acceleration resistance can be approximately expressed as $\left(K=1, i_{\mathrm{TC}}=1\right)$ :

$$
F_{\mathrm{j}}=\left(m+\frac{\sum J_{\mathrm{wh}}}{r_{\mathrm{w}}^{2}}+\frac{J_{\mathrm{TC}} i^{2} i_{0}^{2} \eta_{\mathrm{T}}}{r_{\mathrm{w}}^{2}}+\frac{J_{\mathrm{s}} i_{0}^{2}}{r_{\mathrm{w}}^{2}}\right) \frac{\mathrm{d} u}{\mathrm{~d} t}+\frac{J_{\mathrm{TC}} i i_{0}^{2} \eta_{\mathrm{T}} u}{r_{\mathrm{w}}^{2}} \frac{\mathrm{d} i}{\mathrm{~d} t},
$$

where $J_{\mathrm{TC}}$ is the inertia moment of $\mathrm{TC}\left(\mathrm{kg} \cdot \mathrm{m}^{2}\right)$, $J_{\mathrm{TC}}=J_{\mathrm{p}}+J_{\mathrm{B}}$.

\subsection{Torque Losses of Other Components}

Engine power is transferred to the wheels through various driveline components, such as the transmission. Except for the engine-CVT box driveline, the other components of the driveline, such as the water pump and the generator, also suffer from mechanical losses. Losses are equivalent to the output terminal of the engine, which is expressed as $T_{\text {loss: }}$ :

$$
T_{\text {loss }}=T_{\text {loss }}\left(n_{\mathrm{e}}\right) \text {. }
$$

All parameters above are based on a test car, which was also used to run drum tests.

\section{Bench Test for CVT Efficiency}

The bench test setup (Figure 2) includes two electric motors: an input motor and an output load motor. The CVT box was fixed on the mounting plate, and the input terminal of the CVT box was connected with the output terminal of the input motor through the 


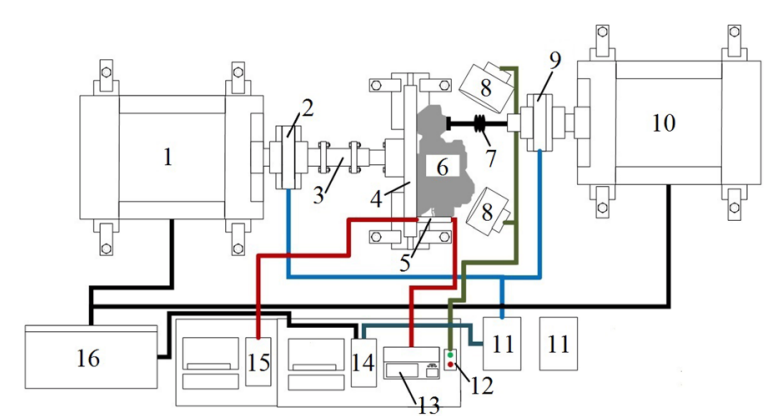

Figure 2 Wiring diagram of the CVT efficiency bench test. 1. Input motor, 2. Input torque and speed sensor, 3. Input coupling, 4. Mounting plate of CVT and bearing seat, 5. TCU of test CVT, 6. Test CVT box, 7. Output universal joint and axle, 8. Cooling fan, 9. Output torque and speed sensor, 10. Output load motor, 11. Torque and speed sensor control cabinet, 12. Cooling fan controller, 13. Data collection equipment, 14. Motor control computer, 15. CVT control computer, 16. Motor control cabinet

input coupling. The differential of the test CVT box was welded, which indicated that the planet gears of the differential were also welded; therefore, the differential function would not work. Only one drive axle generated output torques during the test. Moreover, TCC was engaged. Consequently, the engine angular speed and the angular speed of the CVT primary pulley exhibited the following relationship: $\omega_{e}=\omega_{p}$. The test conditions were achieved by adjusting the input speed of the input motor and the loads of the output motor. During the bench test, the output speed of the input motor was continuously adjusted by adjusting the control signal until the speed measured by the input shaft speed sensor fulfilled our requirement. Thereafter, the loads were gradually increased by adjusting the output load motor to enable the input torques to fulfill the test condition requirements. In the way where the input speed is divided by the ratio of CVT can the output speed be worked out.

\subsection{Loss Measurements of Bench Test Input Equipment}

The losses of input equipment, such as the loss of bearings in the bearing seat and the loss of input coupling, are defined as the torque losses between the input torque sensor and the input terminal of CVT without mounting the CVT box. The data of the input terminal were measured by using the input torque and speed sensor when the input motor worked at different speeds $(1000,1500,2000,2500, \ldots \max )$. Each test condition was repeated thrice, and the average of the results measured from these three tests was recorded as the torque loss of input equipment.

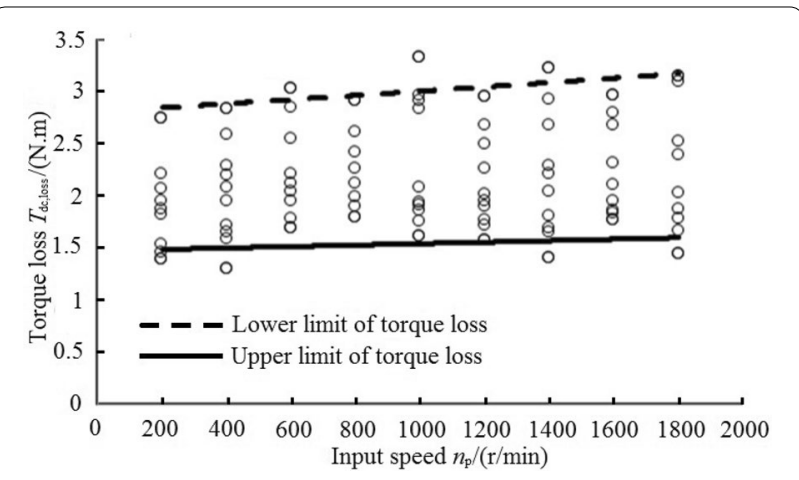

Figure 3 Upper and lower limits of the torque losses of output equipment

\subsection{Loss Measurements of Bench Test Output Equipment}

The losses of output equipment are defined as the torque losses of the output load motor. The torque losses of output equipment exhibited fluctuations based on the measurement data of different output speeds $(200,400,600, \ldots$, $1600 \mathrm{r} / \mathrm{min}$ ). Considerable errors of the measured results would occur if we took the average of the multiple measurements as the torque loss of output equipment. In the actual measurement process, we measured multi-group data at every speed, and a statistical analysis of these data was conducted. Then, we set the upper and lower limits of the torque losses, which were shown in Figure 3.

Lower limit of the torque losses is expressed as $T_{\text {Lower }}$ $(\mathrm{N} \cdot \mathrm{m})$ :

$$
T_{\text {Lower }}=2.8035 e^{7 \times 10^{-5} n_{\mathrm{p}}}
$$

where $n_{\mathrm{p}}$ is the CVT primary pulley speed, which is the input speed of CVT box $(\mathrm{r} / \mathrm{min}) ; T_{\mathrm{dc} \text {,loss }}$ is the torque loss of output load motor $(\mathrm{N} \cdot \mathrm{m})$.

Upper limit of the torque losses is expressed as $T_{\text {Upper }}$ $(\mathrm{N} \cdot \mathrm{m})$ :

$$
T_{\text {Upper }}=1.4704 e^{5 \times 10^{-5} n_{\mathrm{p}}}
$$

\subsection{Bench Test Performance and CVT Efficiency Calculation} Bench test was performed with an existing CVT. Oil temperature was controlled within the range of $80 \pm 2{ }^{\circ} \mathrm{C}$ and monitored with a temperature sensor in real time while running the test. Cooling fans controlled by the temperature sensor were used to dissipate heat from the CVT and run the test at appropriate temperatures. Each test condition must be measured thrice to reduce test errors. Each measurement lasted for $10 \mathrm{~s}$ with a sampling period of $0.05 \mathrm{~s}$. Five ratio points, namely, 2.631, 1.5, 1.05, 0.7, and 0.378 , were evenly selected to run the bench test. The input torque was set at $20 \mathrm{~N} \cdot \mathrm{m}$ to $200 \mathrm{~N} \cdot \mathrm{m}$, with an 
interval of $20 \mathrm{~N} \cdot \mathrm{m}$. The input speed was set at $1000 \mathrm{r} / \mathrm{min}$ to $3000 \mathrm{r} / \mathrm{min}$, with an interval of $500 \mathrm{r} / \mathrm{min}$.

The torque loss measured from the bench test is expressed as $T_{\mathrm{H}, \mathrm{loss}}(\mathrm{N} \cdot \mathrm{m})$ :

$$
T_{\mathrm{H}, \text { loss }}=\left(T_{\mathrm{inc}}-T_{\mathrm{inc}, \text { loss }}\right)-\frac{\left(T_{\mathrm{dc}}+T_{\mathrm{dc}, \text { loss }}\right)}{i i_{0}},
$$

where $T_{\text {inc }}$ is the input torque of input equipment $(\mathrm{N} \cdot \mathrm{m})$, $T_{\text {inc,loss }}$ is the torque loss of input equipment $(\mathrm{N} \cdot \mathrm{m}), T_{\mathrm{dc}}$ is the output torque measured by output torque and speed sensor $(\mathrm{N} \cdot \mathrm{m})$.

The output torque of the CVT output terminal was converted to the input terminal of CVT and then compared with the input torque. The difference between them represented the torque loss of CVT, which was converted to the input terminal of CVT.

The input and output torques of CVT exhibit a relationship with the torque loss of input and output equipment as expressed by

$$
\begin{aligned}
& T_{\mathrm{H}, \mathrm{in}}=T_{\mathrm{inc}}-T_{\text {inc,loss}}, \\
& T_{\mathrm{H}, \mathrm{d}}=T_{\mathrm{dc}}-T_{\mathrm{dc}, \text { loss }},
\end{aligned}
$$

where $T_{\mathrm{H}, \text { in }}$ is the input torque of CVT box $(\mathrm{N} \cdot \mathrm{m}), T_{\mathrm{H}, \mathrm{d}}$ is the output torque of CVT box (N.m).

The equation for CVT efficiencies $\eta_{\mathrm{H} \text {,act }}$, which were measured from the bench test, could be derived from Eqs. (39)-(41). The derived equation is given as

$$
\eta_{\mathrm{H}, \mathrm{act}}=\frac{T_{\mathrm{dc}}+T_{\mathrm{dc}, \text { loss }}}{\left(T_{\mathrm{inc}}-T_{\mathrm{inc}, \text { loss }}\right) i i_{0}}=1-\frac{T_{\mathrm{H}, \text { loss }}}{T_{\mathrm{H}, \mathrm{in}}} .
$$

The torque loss maps of CVT were obtained based on the data calculated using Eq. (39). The torque losses of CVT also have upper and lower limits because of the corresponding limits of output equipment torque losses. Accordingly, the torque loss maps of the average, as well as the upper and lower limits, were constructed. The average, upper limits and lower limits of the torque loss map at a ratio of 0.378 is shown in Figure 4. The contour lines in the figures represent the torque loss lines of different input torques and input speeds at the same ratio.

CVT efficiency maps were constructed based on the data calculated using Eq. (42), which was based on the average values of CVT torque losses. Previous studies $[3-5,14]$ have shown that the efficiency of metal belt CVT can be expressed as a function of ratio and input torque, which is expressed as $\eta=\eta\left(i, T_{\text {in }}\right)$. The CVT efficiency map that changes with ratio and input torque at $\eta_{\mathrm{p}}=2000 \mathrm{r} / \mathrm{min}$ is shown in Figure 5 . As shown in the figure, CVT efficiency changes between $62 \%$ and $92 \%$. Figure 5 also shows that a high CVT efficiency is maintained

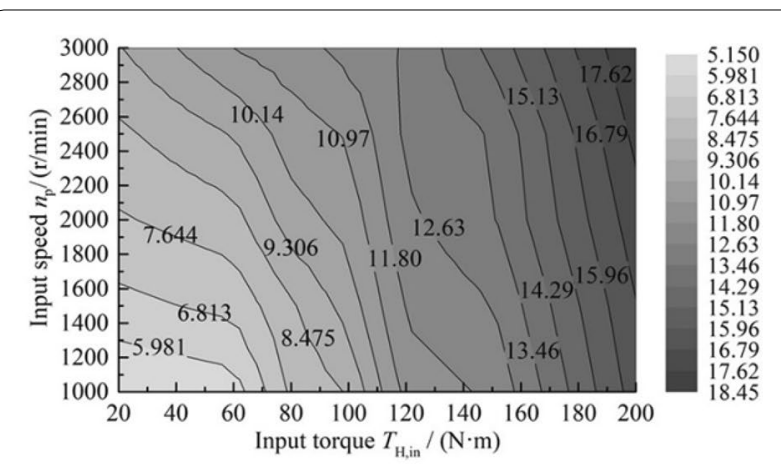

a Average of the torque loss map at 0.378

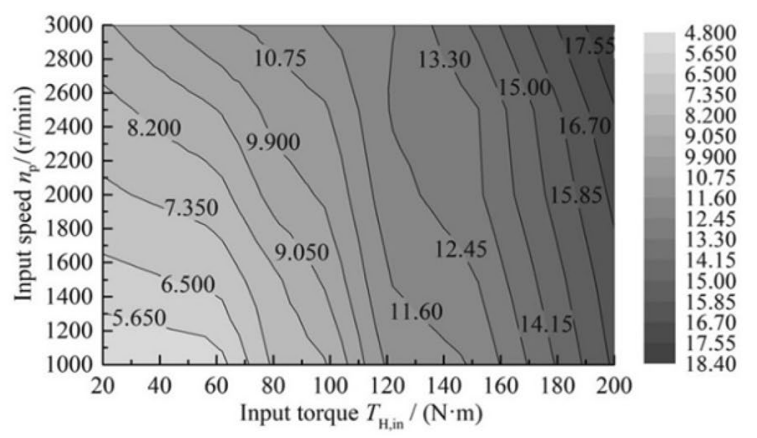

b Upper limits of the torque loss map at 0.378

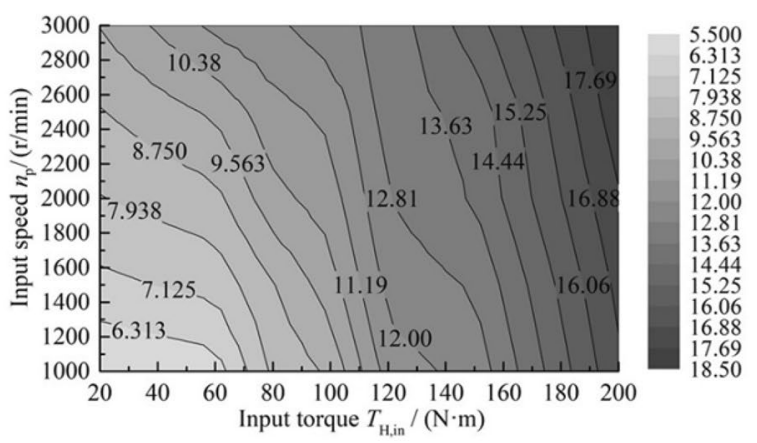

c Lower limits of the torque loss map at 0.378

Figure 4 Torque loss map at 0.378. (a) Average of the torque loss map at 0.378, (b) Upper limits of the torque loss map at 0.378, (c) Lower limits of the torque loss map at 0.378

both within the ratio range of 0.7 to 1.05 and the input torque range of $120 \mathrm{~N} \cdot \mathrm{m}$ to $200 \mathrm{~N} \cdot \mathrm{m}$. CVT efficiency can also be expressed as a function of input speed and input torque, which is given by $\eta=\eta\left(i, T_{\text {in }}\right)$. The CVT efficiency map that changes with input speed and input torque at a ratio of 0.7 is shown in Figure 6. As shown in the figure, CVT efficiency gradually increases when input speed and input torque change from low to high. Figure 6 also shows that high CVT efficiency is maintained when input torque reaches over $100 \mathrm{~N} \cdot \mathrm{m}$. 


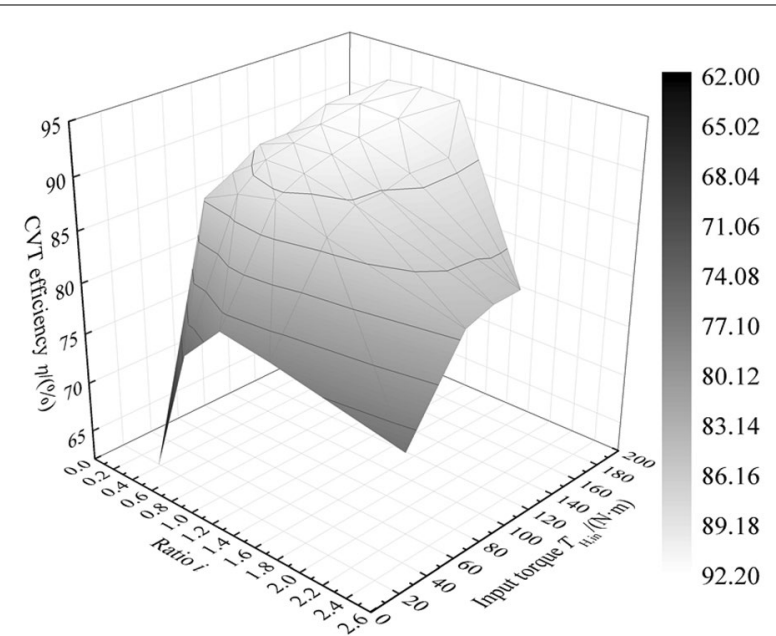

Figure $5 \mathrm{CVT}$ efficiency map that changes with ratio and input torque

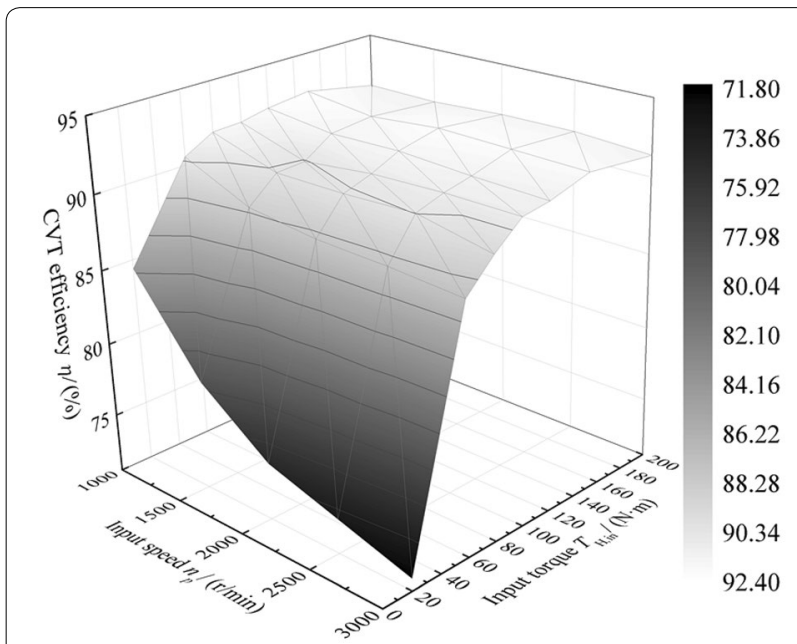

Figure 6 CVT efficiency map that changes with input speed and input torque

The actual torque loss at a certain temperature should be a function that changes with the current ratio, the input speed of CVT, and the input torque. The actual CVT efficiency at a certain temperature should also be a function that changes with the current ratio, the input speed of CVT, and the input torque. The functions are respectively expressed as

$$
\begin{aligned}
& T_{\mathrm{H}, \text { loss }}=T_{\mathrm{H}, \text { loss }}\left(i, n_{\mathrm{p}}, T_{\mathrm{in}}\right), \\
& \eta=1-\frac{T_{\mathrm{H}, \text { loss }}}{T_{\mathrm{in}}}=\eta\left(i, n_{\mathrm{p}}, T_{\mathrm{in}}\right) .
\end{aligned}
$$

\subsection{CVT Efficiency Modeling}

The average efficiency of the test CVT will be $87.71 \%$ if CVT efficiency is evaluated based on the arithmetic average of different ratios. However, such an evaluation cannot determine the changes in CVT efficiency and will reduce the accuracy of the simulation model. Therefore, we used CVT efficiency maps as the efficiency model of the driveline simulation model in this study. Real-time CVT efficiency was obtained based on the piecewise programming lookup method.

CVT efficiency insignificantly changes with an increase input speed when input torque is over $60 \mathrm{~N} \cdot \mathrm{m}$, as shown in Figures 5 and 6 . Therefore, CVT efficiency can be approximately expressed as a single-variable function of input torque. However, CVT efficiency significantly changed with a decrease in ratio. In the practical CVT control process, we can maintain a constant engine speed and adjust vehicle speed by adjusting the ratio. Ratio change is the main factor that causes a change in CVT efficiency in the control process. An independent variable that affects CVT efficiency should be selected in the real-time efficiency simulation model. Therefore, selecting ratio and input torque as the independent variables of CVT efficiency can improve accuracy. The speed intervals of the piecewise programming lookup were divided based on input speed. Real-time CVT efficiency can be obtained from the efficiency map at a certain speed interval based on current ratio, input speed, and input torque.

The upper and lower limits of the preceding speed intervals are the intermediate values of the test speeds, including 1000, 1500, 2000, 2500, and $3000 \mathrm{r} / \mathrm{min}$. The function of the piecewise programming lookup is given by

$$
\eta\left(i, n_{\mathrm{p}}, T_{\text {in }}\right)=\left\{\begin{array}{l}
\eta\left(i, 3000, T_{\text {in }}\right), \quad n_{\mathrm{p}}>2750, \\
\eta\left(i, 2500, T_{\text {in }}\right), \quad 2250<n_{\mathrm{p}} \leq 2750 \\
\eta\left(i, 2000, T_{\text {in }}\right), 1750<n_{\mathrm{p}} \leq 2250 \\
\eta\left(i, 1500, T_{\text {in }}\right), 1250<n_{\mathrm{p}} \leq 1750 \\
\eta\left(i, 1000, T_{\text {in }}\right), n_{\mathrm{p}} \leq 1250 .
\end{array}\right.
$$

CVT efficiency model based on Eq. (45) is connected with the input interface of the driveline simulation model.

\section{Driveline Simulation System Structure and CVT Variogram Generation}

4.1 Driveline Simulation System Structure

CVT ratio and throttle opening must be synthetically controlled to track the target vehicle speed accurately under different conditions [13, 25], and thus, satisfy the need of engine torques and speeds under different target vehicle speeds. The simulation system structure is shown in Figure 7. As shown in the figure, the driver model 


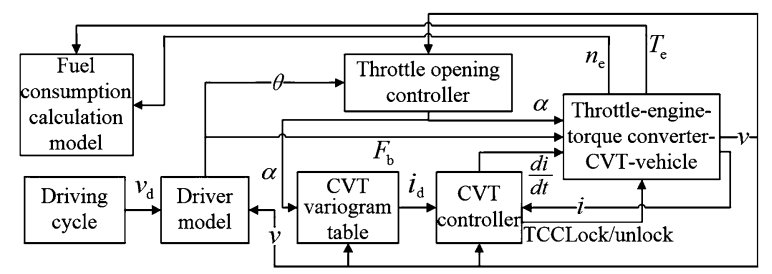

Figure 7 Driveline simulation system structure

outputs the acceleration pedal opening $\theta$ or the braking force $F_{\mathrm{b}}$ based on the difference between target vehicle speed $v_{\mathrm{d}}$ and actual vehicle speed $v$. Then, the throttle opening controller determines target throttle opening $\alpha$ and controls the electronic throttle based on acceleration pedal opening and the actual vehicle speed. Subsequently, the CVT variogram table determines the target ratio $i_{\mathrm{d}}$ based on electronic throttle opening and actual vehicle speed. The CVT controller controls CVT ratio change rate and the unlock/lock signal of TCC based on actual vehicle speed and actual CVT ratio $i$, which assist in tracking target vehicle speed and target ratio to achieve the change in TC transmission modes at a certain vehicle speed. Finally, the fuel consumption calculation model calculates transient fuel consumption and cumulative fuel consumption of driving cycle simulations based on the actual demand engine speed $n_{\mathrm{e}}$ and the actual demand engine output torque $T_{\mathrm{e}}$ of the driveline simulation model.

\subsection{CVT Variogram Generation}

In this study, the CVT variogram is generated based on the original CVT variogram at incomplete throttle openings provided by the transmission factory. The CVT variogram was obtained at all throttle openings by automatically generating the entire CVT variogram using the optimization simulation software. We used the GSPGeneration module in AVL Cruise, which could automatically generate and optimize the shift schedule of the step automatic transmission and CVT variogram. The GSPGeneration module can also generate the required CVT variogram based on the original CVT variogram, the boundary conditions of vehicle performance, road conditions, and the driving behavior of the driver. The calculation process of the CVT variogram in GSP is shown in Figure 8.

The basic parameters of a car simulation model should be inputted into AVL Cruise before running simulations; physical connections and signal circuits should also be established [26]. We inputted the original CVT variogram of the test CVT shown in Figure 9 into the desired input speed tab of the CVT control module. The original CVT variogram is defined in this study as the CVT input

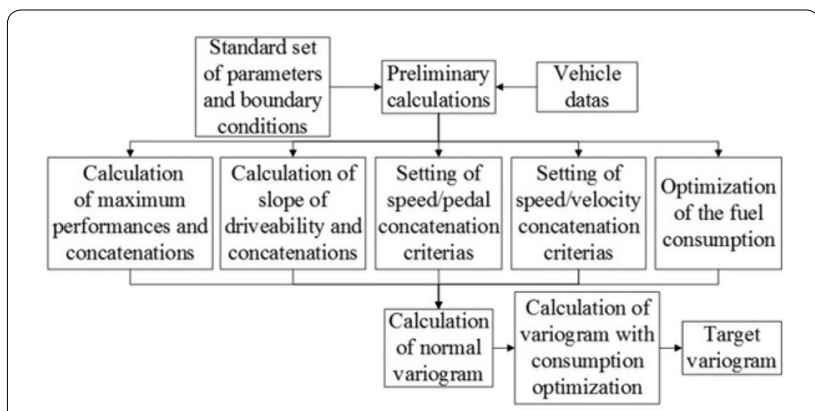

Figure 8 Calculation process of the CVT variogram in GSP

speed variation curve that changes with vehicle speed $u_{\mathrm{a}}$ $(\mathrm{km} / \mathrm{h})$ and throttle opening $\alpha(\%)$. The contour lines in the figures represent different throttle openings.

The CVT variogram generated by using GSP in the simulation is shown in Figure 10, which is the variation curve of the CVT ratio that changes with vehicle speed and throttle opening. This is expressed as

$$
i=i\left(u_{\mathrm{a}}, \alpha\right) .
$$

The region of the CVT variogram shown in Figure 10 is surrounded by the maximum ratio curve, the variation curve of the CVT ratio that changes with vehicle speed, the maximum vehicle speed curve and throttle opening at $0 \%$ and $100 \%$, and the minimum ratio curve.

The CVT variogram such as the one shown in Figure 10 is the optimal economic variogram that can be generated by using optimization software tools and an optimization algorithm. The quantity of calibration test works via bench tests and road tests can be decreased because of this feature [27].

\section{Test Cycles and Conditions}

Numerous researchers have studied transmission efficiency and fuel economy by conducting powertrain bench tests using a real gasoline engine as the power source and dynamometers as the load sources in addition to a gearbox and drive axles [7, 13]. Achieving driving cycles in bench tests are relatively more complicated than that in simulation models. Bench tests that use gasoline engines and dynamometers can be displaced by the forecast simulation model. In addition, matching system parameters with existing test data of powertrain components using the simulation model is more convenient than bench tests.

The simulation test aims to verify the forecast accuracy of the car driveline simulation model based on CVT efficiencies measured from a bench test. The fuel consumption tests include driving cycles and constant velocity condition. 


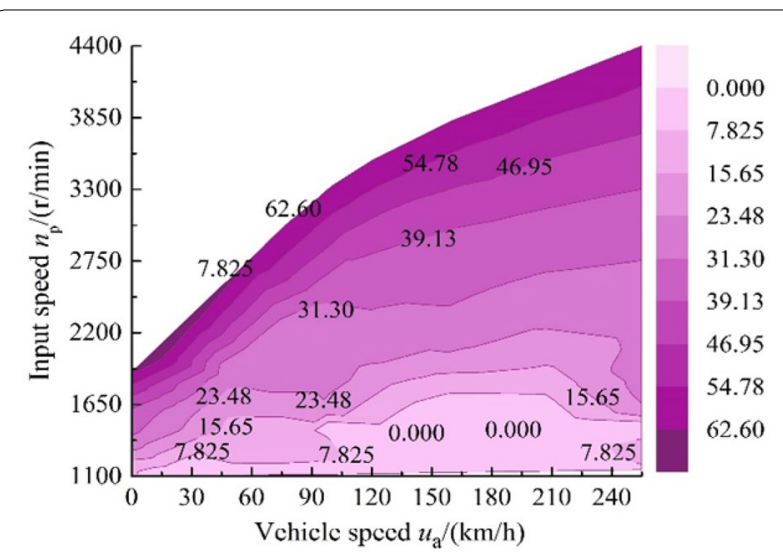

Figure 9 Original CVT variogram

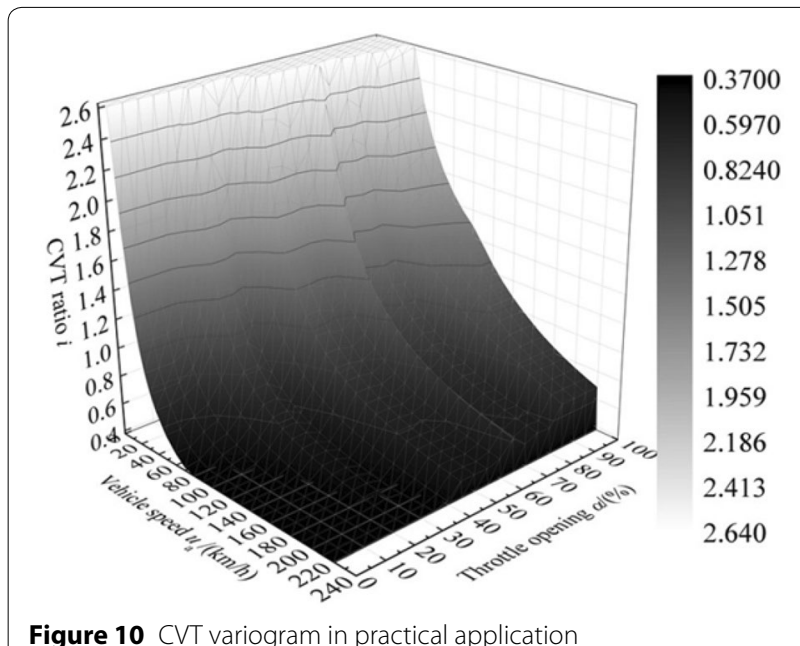

\subsection{Driving Cycle}

Driving cycles in the world mainly include those found in Europe, the United States, and Japan. The model driving cycle exemplified by ECE-15 cycle, which is a part of vehicle regulations of Economic Commission for Europe (ECE), and the transient driving cycle exemplified by the Federal Test Program (FTP) are extensively used worldwide [28]. ECE-15 cycle is also called urban driving cycle (UDC). In fact, numerous researchers have analyzed the aforementioned driving cycles [29-31]. Therefore, we selected the New European Driving Cycle (NEDC) in this study, which included four repeated UDCs and one Extra-Urban driving cycle (EUDC), and the United States' Highway Fuel Economy Test (HWFET) (Figures $11,12,13,14)$ to run fuel consumption simulations. NEDC, including urban and suburban conditions, was used to simulate actual urban and suburban road conditions, whereas HWFET was used to simulate highway conditions.

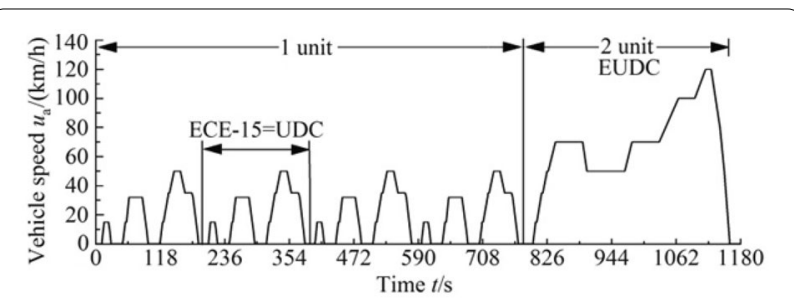

Figure 11 NEDC of Europe

\subsection{Constant Velocity Condition}

Constant velocity tests should include $90 \mathrm{~km} / \mathrm{h}$ and $120 \mathrm{~km} / \mathrm{h}$ constant velocity tests according to the China National Standard GB/T12545.1-2008 [32]. In this study, we ran constant velocity simulation tests at speeds of 60,90 and $120 \mathrm{~km} / \mathrm{h}$ in the car driveline simulation model.

Likewise, driving cycles and constant velocity conditions were run in real car drum tests in Section 6.

The car driveline simulation model was set with a load of $100 \mathrm{~kg}$. Corners, ramps, and tire sliding were not considered while running the simulations. The velocity-time curves under different driving conditions were inputted into the driver model. The driveline simulation model tracked target vehicle speed according to the process shown in Figure 7. Transient and cumulative fuel consumptions in the current period were calculated according to the actual demands of engine speed and output torque. calculated in the simulation.

\section{Results of the Contrastive Analysis of the Real Car Drum Test and the Simulation}

\subsection{Real Car Drum Test}

\subsubsection{Parameters of Chassis Dynamometer and Test Car}

The drum tests were conducted on a four-drum chassis dynamometer (Figure 15). The power performance tests of two-wheel and four-wheel drive cars, fuel economy tests, and reliability tests can be conducted on the chassis dynamometer. The vehicle emission test system comprises the four-drum chassis dynamometer, a programmable computer, a constant volume sampling system, a gasoline dilution pipeline, a gasoline particle sampling unit, and an emission analysis system. The parameters of the four-drum chassis dynamometer are listed in Table 1. Fuel emission test data were collected from controller area network (CAN) signals and the emission test system (Table 2).

The test car is a particular model equipped with a CVT gearbox that has been launched in the market. The parameters of the car are listed in Table 3. The chassis dynamometer was set according to the car parameters. 


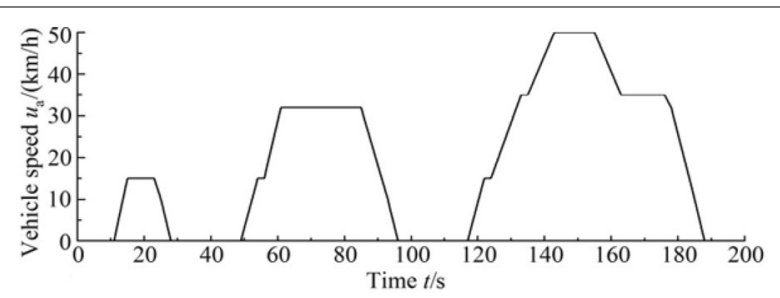

Figure 12 UDC

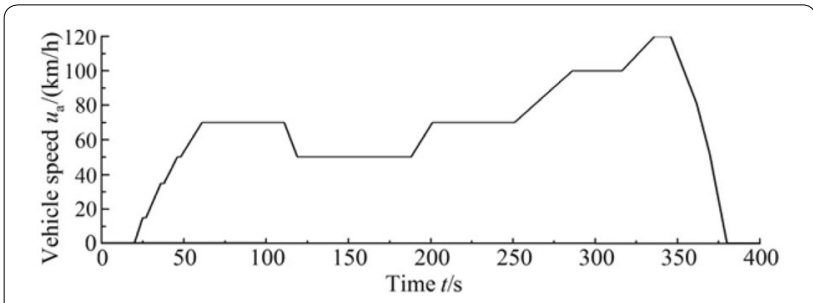

Figure 13 EUDC

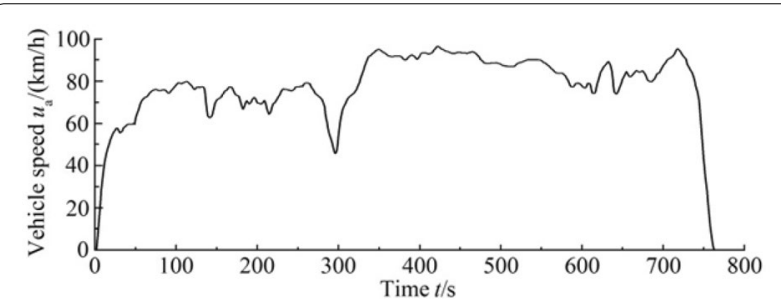

Figure 14 HWFET of the United States

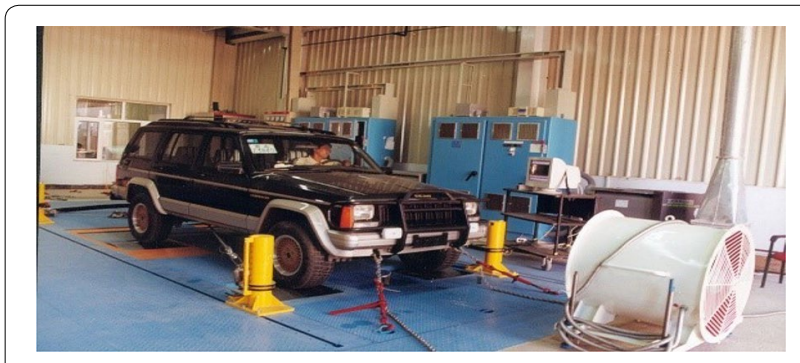

Figure 15 Four-drum chassis dynamometer

\subsubsection{Driving Resistance Setting and Drum Test}

The chassis dynamometer was calibrated before the test according to the China National Standard GB/T12545.12008. The inertia moments of the drums were set to simulate the inertia moments of the car. The power absorbing and loading device was set to simulate the driving resistance. The driving resistance is expressed as

$$
F=3.71 u_{\mathrm{a}}^{2}+5 \times 10^{-13} u_{\mathrm{a}}+144.2 .
$$

The rear wheels of the test car were fixed and electronic stability control (ESC) was turned off. Hence, the test car could be driven in a front-wheel drive mode. An experienced driver and a front passenger, whose weights were approximately $100 \mathrm{~kg}$, were asked to ride the test car.

Drum tests were conducted based on the velocitytime curves of the driving cycles. The driver controlled the acceleration and brake pedals to maintain actual vehicle speed between the upper and lower limits of the velocity-time curve. Each driving cycle was run twice. The data recorded by the emission test system of the dynamometer were used as the test result. The cumulative fuel consumption at the end of each driving cycle was recorded, and the average fuel consumption of each cycle was considered as the effective test value.

Constant velocity tests were conducted at 60,90 , and $120 \mathrm{~km} / \mathrm{h}$ according to the China National Standard GB/ T12545.1-2008. The constant velocity test at each vehicle speed, which included a driver control mode and an automatic cruise mode, was run twice. The average fuel consumption in the two test modes was recorded.

\subsubsection{Results of Real Car Drum Test}

The results of the real car drum test are listed in Table 4.

All the test results of each condition in the two tests are sufficiently effective. All the results are listed as the average value of each condition to simplify the comparison and analysis processes.

\subsection{Contrastive Analysis and Discussion}

The CVT efficiencies of the driving cycles obtained in the simulations are shown in Figures 16, 17, 18, 19, 20, 21, 22, 23. The CVT efficiency curves in the figures indicate the changing trend of CVT efficiency, which changes with the CVT ratio, input speed, and input torque. When vehicle speed is $0 \mathrm{~km} / \mathrm{h}$, the input speed of CVT is $0 \mathrm{r} / \mathrm{min}$ and CVT efficiency is $100 \%$. When the driver model outputted braking force, the car decelerated and the engine generated braking torques, which are negatively shown in the Figures Urban driving cycles are characterized by complex road conditions. The CVT box changes the ratio frequently and drastically, thereby leading to a drastic change in CVT efficiency, as shown in Figures 16, 17, 18, 19. The engine mostly operates in uneconomical areas at relatively low output torques, whereas the CVT works at high ratios. Consequently, low CVT efficiencies are produced, which lead to a high CVT torque loss and increase fuel consumption. Thus, fuel consumption in urban driving cycles is higher than that in suburban or highway driving cycles. The ratios in the EUDC and HWFET test cycles are more stable than those shown in NEDC and UDC test cycles. Although the input torques shown in 
Table 1 Parameters of four-drum chassis dynamometer

\begin{tabular}{ll}
\hline Parameter & Value \\
\hline Specification and model & $\begin{array}{c}\text { Burke E. Porter Machinery } \\
\text { Company U.S.A, Model } \\
\end{array}$ \\
& 3260 \\
Drum diameter $(\mathrm{mm})$ & $1219.2 \pm 0.3$ \\
Range of axle base $(\mathrm{mm})$ & $2000-3600$ \\
Absorbing power $(\mathrm{kW})$ & $\geq 140 \times 2$ \\
Measure range of torque $(\mathrm{N} \cdot \mathrm{m})$ & 6519 \\
Driving model & FWD/RWD; 4WD \\
Maximum speed $(\mathrm{km} / \mathrm{h})$ & 220 \\
Maximum load $(\mathrm{kg})$ & 2000 \\
Inertia mass simulation range $(\mathrm{kg})$ & $454-5448$ \\
Inertia mass simulation accuracy & $\leq \pm 1 \%$ \\
\hline
\end{tabular}

Table 2 Data to be collected in drum tests

\begin{tabular}{ll}
\hline Measure parameter & Data source \\
\hline Engine speed & CAN signal \\
Engine output torque & CAN signal \\
$\begin{array}{l}\text { Real-time fuel consumption calculated } \\
\text { by ECU }\end{array}$ & CAN signal \\
Throttle opening degree & CAN signal \\
CVT ratio & CAN signal \\
Vehicle speed & CAN signal \\
Driving time & Vehicle emission test system \\
Distance & Vehicle emission test system \\
Real-time fuel consumption & Vehicle emission test system \\
\hline
\end{tabular}

Table 3 Parameters of test car

\begin{tabular}{lc}
\hline Parameter & Value \\
\hline Maximum power of engine $(\mathrm{kW})$ & 249 \\
Length $(\mathrm{mm})$ & 5003 \\
Width $(\mathrm{mm})$ & 1830 \\
Height $(\mathrm{mm})$ & 1490 \\
Axle base $(\mathrm{mm})$ & 2768 \\
Front wheel base $(\mathrm{mm})$ & 1585 \\
Rear wheel base $(\mathrm{mm})$ & 1585 \\
Curb weight $(\mathrm{kg})$ & 1581 \\
Maximum speed $(\mathrm{km} / \mathrm{h})$ & 207 \\
\hline
\end{tabular}

EUDC after $200 \mathrm{~s}$ (a high-speed period) and in HWFET drastically change, the CVT input torques remain sufficiently high. The engine operates at points that are mostly economical, where ratios are sufficiently low to maintain high CVT efficiency for a relatively long period and decrease CVT torque loss, thereby leading to reduced fuel consumption.
One set of the effective drum test results is compared with the simulation results (Figures 16, 17, 18, 19, 20, 21, 22, 23). The figures also show the changes in real input torque, input speed, and real ratio in the bench test. The simulation results agree well with the real values, which indicates that the simulation forecast model is sufficiently specific to forecast fuel economy. However, errors between the simulation results and drum test results still exist, which can lead to errors in fuel economy forecast.

The fuel consumption of the driving cycles (calculated using the driveline simulation model based on CVT efficiencies measured from the bench tests) and the average fuel consumption of the drum tests are compared in Table 5. The simulation results have the largest absolute value of errors at $4.099 \%$ compared with the average drum test results of each cycle, thereby indicating that the simulation results are accurate and the driveline simulation model can effectively forecast fuel consumption.

CVT efficiencies obtained in the simulations under constant velocity condition are presented in Figure 24. As shown in the figure, CVT efficiency gradually increases with a decrease in ratio and an increase in vehicle speed, which requires increasing input torque.

Figure 25 shows the ratios, input speeds, and input torques of the simulation results and the bench test results in every mode. The fuel consumption values under constant velocity condition, which are obtained from the simulations and drum tests, are also compared in Figure 26. The average values of the bench test results in every mode are calculated to compare with the simulation results. The simulation model exhibits more accurate forecasts of the driver control mode below $90 \mathrm{~km} / \mathrm{h}$ under constant velocity condition. Furthermore, the simulation results under constant velocity condition at vehicle speeds of $60 \mathrm{~km} / \mathrm{h}$ and $90 \mathrm{~km} / \mathrm{h}$ have $0.353 \%$ and $3.273 \%$ absolute values of errors, respectively, compared with the average results of the driver control mode drum tests (Figure 26). The accuracy of the simulation model is reduced at a vehicle speed of $120 \mathrm{~km} / \mathrm{h}$, and the simulation result has a $5.449 \%$ absolute value of error compared with the average results of the driver control mode drum tests, which is still acceptable in the engineering point of view. Moreover, the errors between the simulation results and the average results of the automatic cruise drum tests are stable. The absolute values of errors at 60,90 , and $120 \mathrm{~km} / \mathrm{h}$ are $4.2 \%, 4.07 \%$, and 4.197 respectively, which have minimal fluctuations, thereby confirming that the simulation model is effective under constant velocity condition. Figure 25 shows that errors exist between the simulation results and the drum tests. However, the results in Figure 26 also indicate that the errors do not significantly influence the forecast accuracy of fuel economy under constant velocity condition. 
Table 4 Results of real car drum test

\begin{tabular}{lll}
\hline Working condition & Number of measurement & $\begin{array}{l}\text { Result } \boldsymbol{Q}_{\mathbf{s}} \\
(\mathbf{L} / \mathbf{1 0 0} \mathbf{~ k m})\end{array}$ \\
\hline NEDC & 2 & 7.18 \\
UDC & 2 & 9.05 \\
EUDC & 2 & 6.06 \\
HWFET & 2 & 5.17 \\
$60 \mathrm{~km} / \mathrm{h}$ & & \\
Cruise & 2 & 4.38 \\
Driver control & 2 & 4.18 \\
$90 \mathrm{~km} / \mathrm{h}$ & & \\
Cruise & 2 & 5.10 \\
Driver control & 2 & 5.06 \\
120 km/h & & \\
Cruise & 2 & 6.81 \\
Driver control & 2 & 6.73 \\
\hline
\end{tabular}

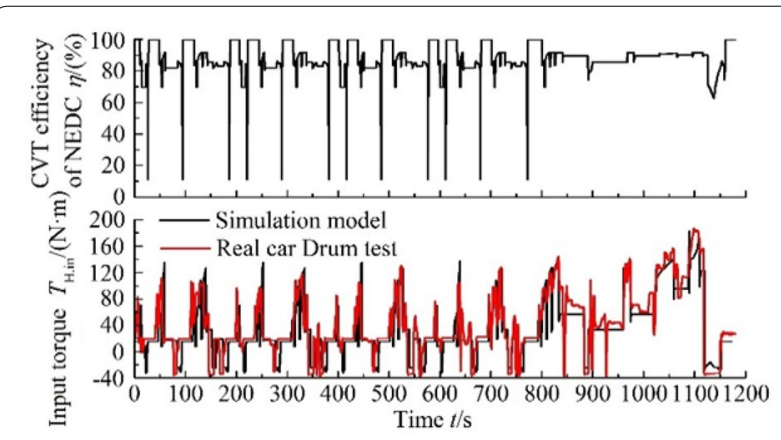

Figure 16 Simulation results of NEDC (a)

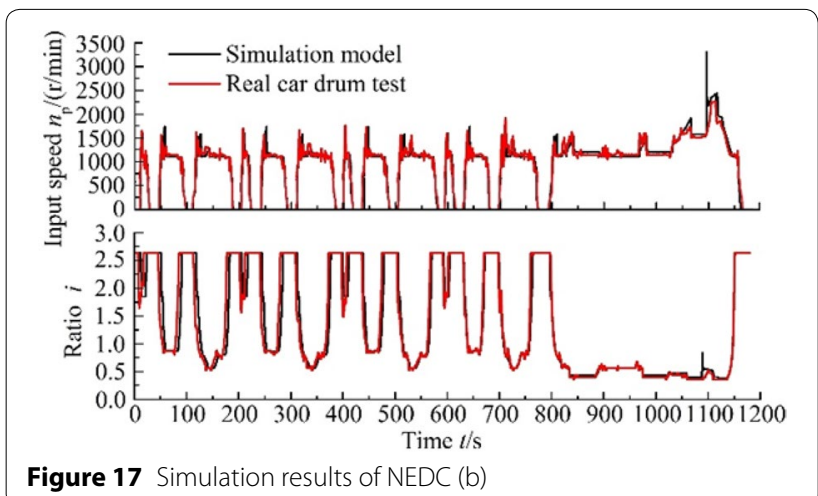

Compared with the results under constant velocity condition, a larger error in fuel economy forecast occurs under high-speed condition with a low ratio, such as $120 \mathrm{~km} / \mathrm{h}$, thereby resulting in a larger error of over $5 \%$ in fuel economy forecast in driver control mode. Less periods of high-speed condition close to $120 \mathrm{~km} / \mathrm{h}$ occur in driving cycles, and thus, high-speed errors that can cause larger forecast errors do not significantly influence the simulation. The car mostly runs at a vehicle speed below $100 \mathrm{~km} / \mathrm{h}$, and the simulation model can maintain good accuracy with errors smaller than $4.2 \%$. Therefore, the simulation results of the driving cycles exhibit better accuracy.

Assumptions and ideal simplifications of simulation model can cause the simulation errors. In addition, the errors between the simulation results and the real car drum test are simultaneously attributed to the CVT variogram and CVT efficiency model. The variogram used for the simulation of fuel economy should be an optimal economic variogram. In this study, such variogram is generated based on the original CVT variogram at incomplete throttle openings. However, the variograms used in the Transmission Control Unit (TCU) of the real car calibrated by the transmission factory are more complicated and consider more driving conditions, temperature conditions, and altitude conditions. The variogram used in the simulation is optimized based on the boundary conditions of vehicle performance, road conditions and the driving behavior of the driver, but numerous elements such as temperatures and altitudes are not fully considered. Consequently, the errors between the variogram generated in this study and the variogram used in the TCU are unavoidable. The contrastive results shown in Figures 16, 17, 18, 19, 20, 21, 22, 23 indicate that the simulation ratio does not completely follow the real ratio, thereby resulting in errors in input torques and input speeds between the simulations and the real car drum tests, which can lead to fuel economy calculation errors. Similarly, the contrastive results of the ratios, input torques, and input speeds under constant velocity condition shown in Figures 25, 26 indicate that the errors are attributed to the same reason. Moreover, the ratio errors between the simulation results and drum test results affect fuel economy forecast more evidently, particularly at $90 \mathrm{~km} / \mathrm{h}$ and $120 \mathrm{~km} / \mathrm{h}$ in driver control mode. In addition, the CVT efficiency model is based on the efficiency bench test within an ideal oil temperature range of $80 \pm 2{ }^{\circ} \mathrm{C}$ and the effects of temperatures on transmission efficiency are also not considered in the preceding assumption. The oil temperatures collected from CAN signals in the real car drum test are between $69^{\circ} \mathrm{C}$ and $109{ }^{\circ} \mathrm{C}$, which are influenced by working time and conditions. The longer the time and the higher the speed of CVT runs, the higher the oil temperature is. Therefore, the errors between the temperatures of the simulations and drum tests lead to the errors in real-time CVT efficiencies, which affect fuel economy forecast. To decrease errors, a better optimization algorithm that considers more conditions should be used to generate a better CVT 


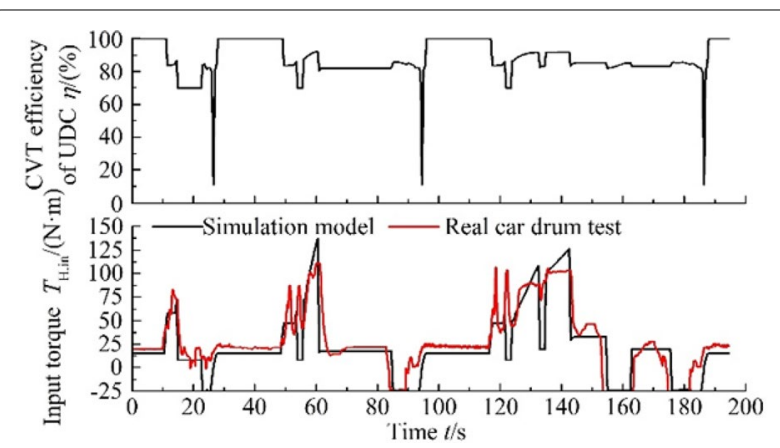

Figure 18 Simulation results of UDC (a)

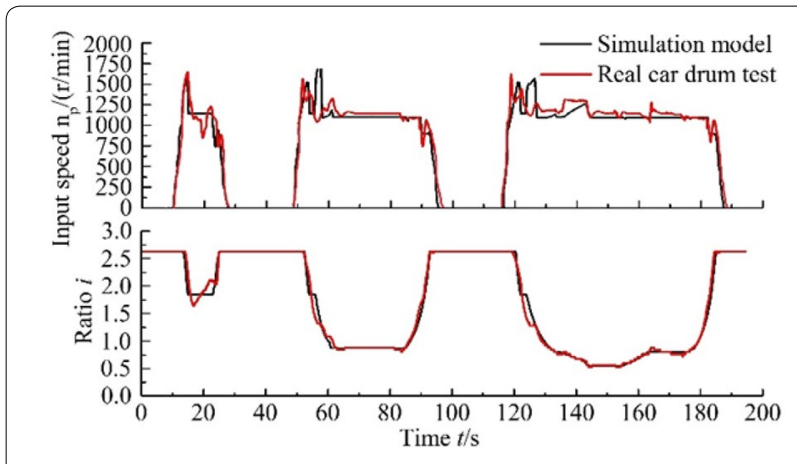

Figure 19 Simulation results of UDC (b)

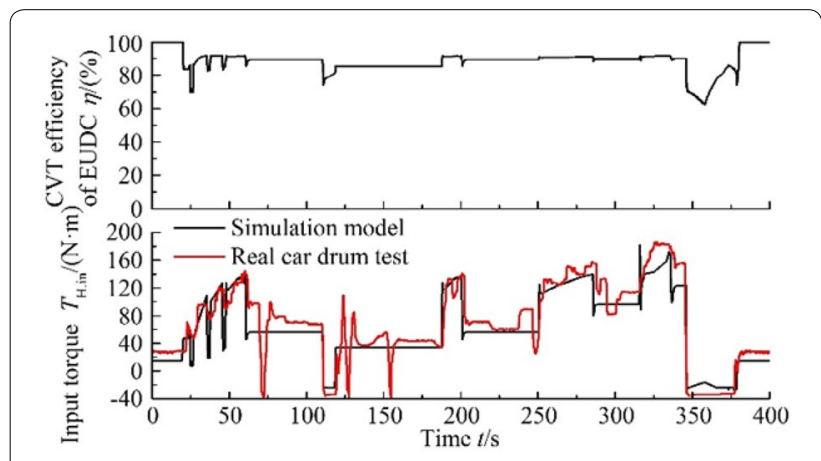

Figure 20 Simulation results of EUDC (a)

variogram and a better CVT efficiency model that considers more temperature conditions should be built in future works.

\section{Conclusions}

(1) A method for combining computer simulation forecasts with bench tests is proposed. A car driveline simulation model based on CVT efficiencies measured from a bench test and the driveline data of

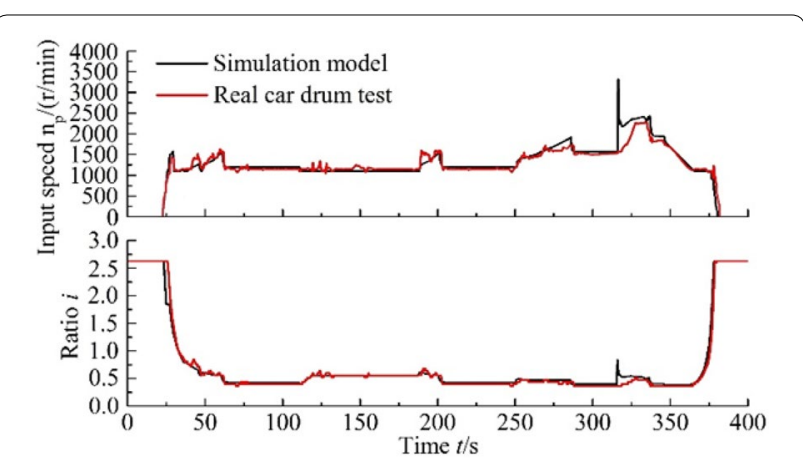

Figure 21 Simulation results of EUDC (b)

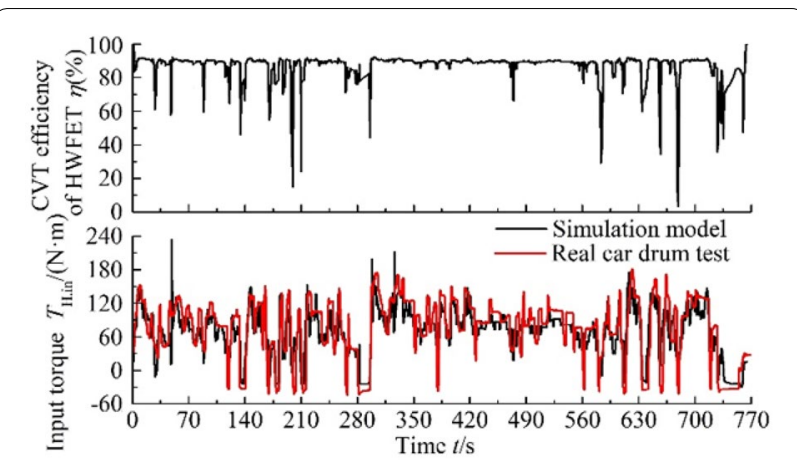

Figure 22 Simulation results of HWFET (a)

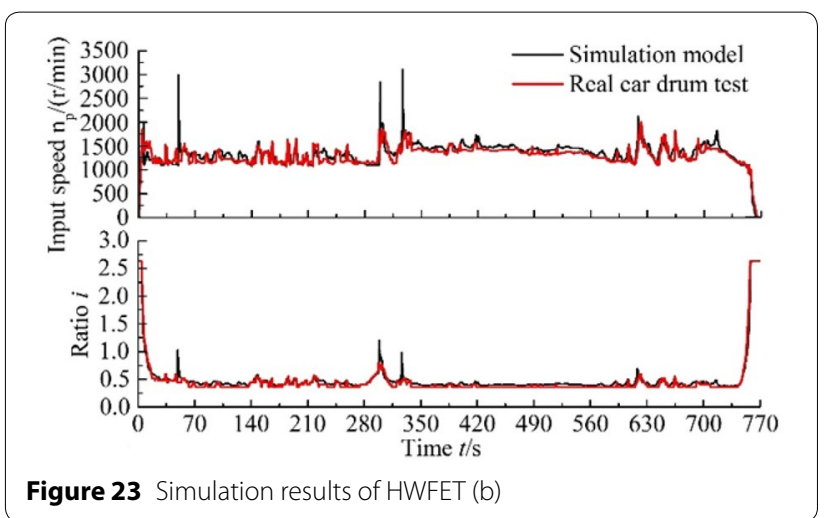

Table 5 Fuel consumption in different driving cycle

\begin{tabular}{llll}
\hline Driving cycle & $\begin{array}{l}\text { Drum test result } \\
(\mathbf{L} / \mathbf{1 0 0} \mathbf{~ k m})\end{array}$ & $\begin{array}{l}\text { Simulation result } \\
(\mathbf{L} / \mathbf{1 0 0} \mathbf{~ k m})\end{array}$ & Error (\%) \\
\hline NEDC & 7.18 & 7.324 & 1.987 \\
UDC & 9.05 & 9.421 & 4.099 \\
EUDC & 6.06 & 6.100 & 0.660 \\
HWFET & 5.17 & 5.005 & 3.191 \\
\hline
\end{tabular}




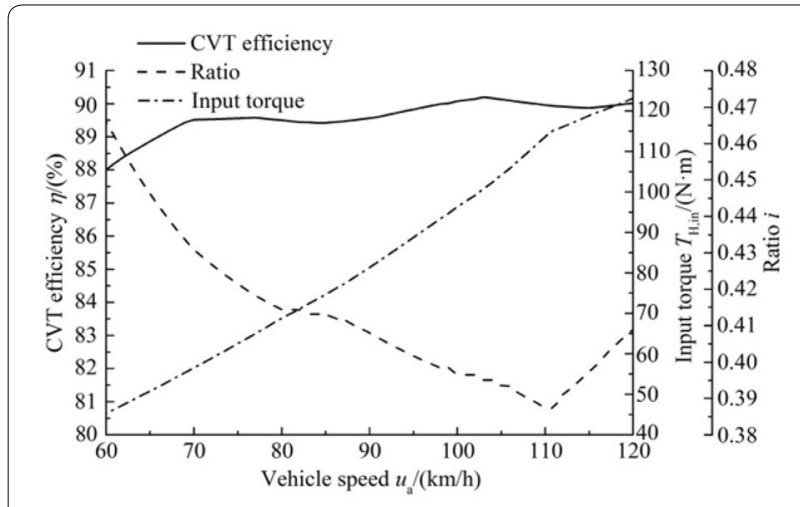

Figure 24 Simulation results under constant velocity condition

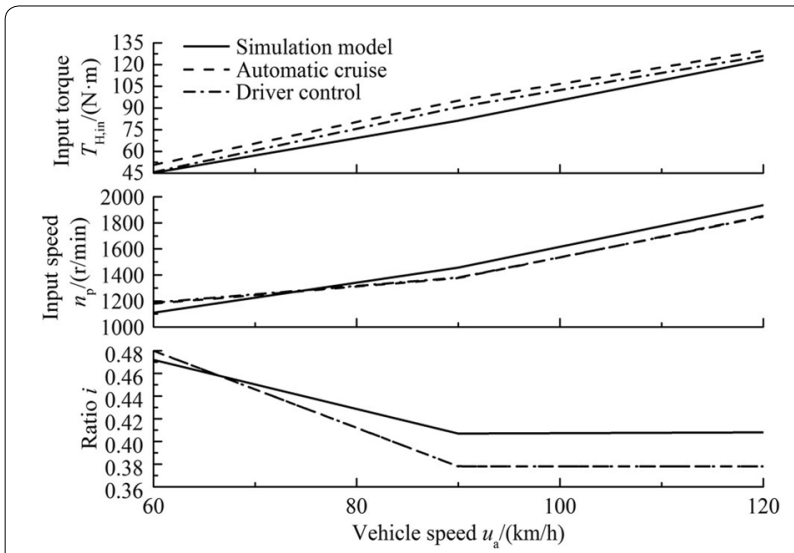

Figure 25 Contrastive diagram of input torque, input speed, and ratio under constant velocity condition

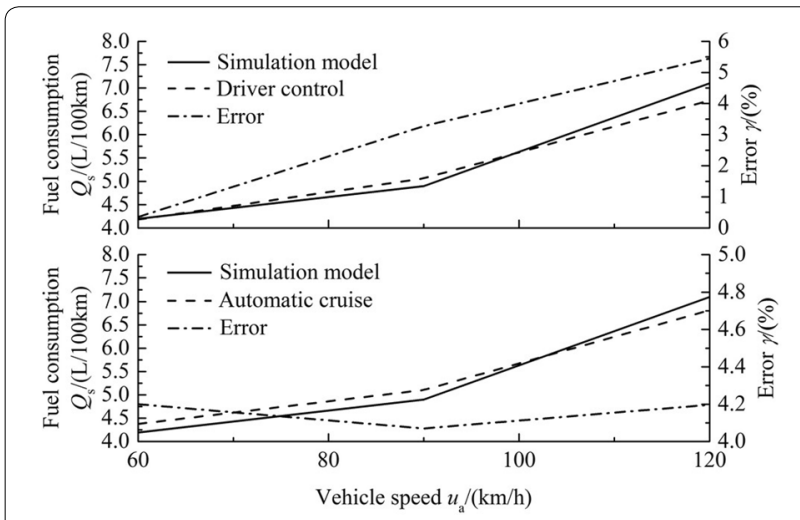

Figure $\mathbf{2 6}$ Contrastive diagram of fuel consumption under constant velocity condition

a real CVT car is constructed to forecast the fuel economy of a car equipped with a CVT box. The proposed method and model can simplify the pro- cess of studying the effects of CVT efficiency on car fuel economy compared with that through bench and road tests.

(2) A CVT efficiency model based on the function of the piecewise programming lookup derived out from bench test data is developed. The car driveline simulation model can calculate the changing value of CVT efficiency in real time based on real-time ratio, input speed, and input torque.

(3) An optimal economic variogram based on the original CVT variogram, the boundary conditions of vehicle performance, road conditions, and the driving behavior of the driver is generated and inputted into the simulation model as the CVT control strategy. The variogram exhibits good performance in the simulations.

(4) Driving cycles and constant velocity condition are compared between the simulation results and the drum test results. The car driveline simulation model demonstrates better accuracy in terms of driving cycles and constant velocity condition at speeds below $120 \mathrm{~km} / \mathrm{h}$. The largest error of the results between the car driveline simulations and the real car drum tests for driving cycles is $4.099 \%$, which is $5.449 \%$ under constant velocity condition in driver control mode and $4.2 \%$ under constant velocity condition in automatic cruise mode. Good agreements among the ratios, input speeds, and input torques are found between simulation results and the real car drum test results. The contrastive results confirm that the car driveline simulation model based on CVT efficiencies, which are measured from a bench test, exhibits good performance and can accurately forecast fuel consumption under different driving conditions.

\section{Authors' contributions}

$Y$-LL, KL and Y-ZJ were in charge of the whole trial; Y-ZJ wrote the manuscript; Y-ZJ, YF, KL, YZ and Z-JL assisted with sampling and laboratory analyses. All authors read and approved the final manuscript.

\section{Author Details}

${ }^{1}$ State Key Laboratory of Automotive Simulation and Control, Jilin University, Changchun 130022 , China. ${ }^{2}$ Faw Jiefang Automotive Co., Ltd, Changchun 130011, China. ${ }^{3}$ United Automotive Electronic Systems Co., Ltd, Shanghai 200120, China. ${ }^{4}$ China North Vehicle Research Institute, Beijing 100072, China.

\section{Authors' Information}

Yu-Long Lei, born in 1970, is currently a full professor at State Key Laboratory of Automotive Simulation and Control, College of Automotive Engineering, Jilin University, China. He received his PhD degree from Jilin University, China, in 1999. His research interests include vehicle automatic transmission system and automotive hydrodynamic drive.

Yu-Zhe Jia, born in 1991, is currently an engineer at Faw Jiefang Automotive Co., Ltd, Changchun, China. He received his master degree from Jilin University, China, in 2017. His research interests include automotive powertrain system theory and control. 
Yao Fu, born in 1986, is currently a teacher at State Key Laboratory of Automotive Simulation and Control, College of Automotive Engineering, Jilin University, China. He received his PhD degree from Jilin University, China, in 2015. His research interests include vehicle automatic transmission theory and control technology.

Ke Liu, born in 1990, is currently a PhD candidate at State Key Laboratory of Automotive Simulation and Control, College of Automotive Engineering, Jilin University, China. He received his bachelor degree from Changan University, China, in 2012. His research interests include automotive powertrain system theory and control.

Ying Zhang, born in 1990, is currently an engineer at United Automotive Electronic Systems Co., Ltd, Shanghai, China. He received his master degree from Jilin University, China, in 2018. His research interests include automotive powertrain system theory and control.

Zhen-Jie Liu, born in 1986, is currently a researcher at China North Vehicle Research Institute, Beijing, China. He received his PhD degree from Jilin University, China, in 2013. His research interests include vehicle automatic transmission theory and control technology.

\section{Competing Interests}

The authors declare that they have no competing interests.

\section{Funding}

Supported by National Natural Science Foundation of China (Grant No. 51575220), and International S\&T Cooperation Program of China (Grant No. 2014DFA71790).

\section{Publisher's Note}

Springer Nature remains neutral with regard to jurisdictional claims in published maps and institutional affiliations.

\section{Received: 29 April 2016 Accepted: 21 September 2018}

Published online: 04 October 2018

\section{References}

[1] D Z Zhang, Z Q Tang, Y D Zhang, et al. The simulated program of vehicle dynamics and fuel economy. Automotive Engineering, 1985(3): 2-12. (in Chinese)

[2] Y Lin. Automotive performance optimization method and program design. Bus Technology and Research, 1996, 18(3): 131-137. (in Chinese)

[3] S Akehurst, N D Vaughan, D A Parker, et al. Modeling of loss mechanisms in a pushing metal V-belt continuously variable transmission, part 1 torque losses due to band friction. Proc. Inst. Mech. Eng., Part D: Journal of Automobile Engineering, 2004, 218(11): 1269-1281.

[4] S Akehurst, N D Vaughan, D A Parker, et al. Modeling of loss mechanisms in a pushing metal V-belt continuously variable transmission, part 2 pulley deflection losses and total torque loss validation. Proc. Inst. Mech. Eng., Part D: Journal of Automobile Engineering, 2004, 218(11): 1283-1293.

[5] S Akehurst, N D Vaughan, D A Parker, et al. Modeling of loss mechanisms in a pushing metal v-belt continuously variable transmission, part 3 belt slip losses. Proc. Inst. Mech. Eng, Part D: Journal of Automobile Engineering, 2004, 218(11): 1295-1306.

[6] N S Cheng, W Liu, D Z Guo, et al. Experimental study of transmission efficiency for metal pushing V-belt type CVT. Journal of Northeastern University (Natural Science), 2000, 21(4): 394-396. (in Chinese)

[7] H C Huang, J C Xu, J B Wen. Test and analysis CVT efficiency. Drive System Technique. 2010, 24(2): 37-41. (in Chinese)

[8] TWang, H L Li. Research on the influence of gear precision on the transmission efficiency. Bus \& Coach Technology and Research, 2015(5): 56-59. (in Chinese)

[9] Y Gao. The influence factor analysis and experimental study of the minicar gearbox transmission efficiency. Wuhan: Wuhan University of Technology, 2013. (in Chinese)

[10] P P Li, HY Dou, L F Zhang, et al. Analysis and experimental research of oil influence on gear transmission efficiency. Agricultural Equipment \& Vehicle Engineering, 2014, 52(5): 56-60. (in Chinese)
[11] P D Patel, J M Patel. An experimental investigation of power losses in manual transmission gear box. International Journal of Applied Research in Mechanical Engineering, 2012, 2(1): 1-5.

[12] C Zhu, H Liu, J Tian, et al. Experimental investigation on the efficiency of the pulley-drive CVT. International Journal of Automotive Technology, 2010, 11(2): 257-261.

[13] Y Luo, D Y Sun, D T Qin, et al. Fuel optimal control of CVT equipped vehicles with consideration of CVT efficiency. Journal of Mechanical Engineering, 2010, 46(4): 80-86. (in Chinese)

[14] Y C Cai. Research on the fuel economy and system reliability of metal V-belt CVT. Changsha: Hunan University, 2011. (in Chinese)

[15] Xi Wang. Research of automobile fuel economy based on transmission efficiency. Chongqing: Chongqing University, 2010. (in Chinese)

[16] FW Yan, F Hu, S P Tian, et al. Simulation and parameter sensitivity analysis of automobile fuel economy. Journal of Wuhan University of Technology (Information \& Management Engineering), 2010, 32(2): 261-264. (in Chinese)

[17] DY Huang. A feasible method for forecasting fuel economy. Journal of Jiangsu University of Science and Technology, 1996, 17(4): 16-19. (in (hinese)

[18] XY Yang, G Wang, R K Zhou, et al. Research and simulation analysis method of automobile fuel economy. Journal of Chongqing University of Technology (Natural Science), 2014, 28(8): 6-12. (in Chinese)

[19] J Gong, D X Hao, Y Chen, et al. Study on shift schedule saving energy of automatic transmission of ground vehicles. Journal of Zhejiang UniversitySCIENCE A (Applied Physics \& Engineering), 2004, 5(7): 878-883.

[20] J G Cao, D T Qin, J J Hu, et al. Application of hydraulic torque converter incorporated in mechanical continuously variable transmission. Journal of Chongqing University (Natural Science Edition), 2002, 25(8): 5-9. (in Chinese)

[21] L G CHEN, S M LIU, Y F ZHENG, et al. Simulation and test of the lock process for hydrodynamic torque converter. Chinese Hydraulic and Pneumatics, 2012, (4): 27-29. (in Chinese)

[22] H S Zhang, Y Shi, L L Qin, et al. Slip control strategy of torque converter lock-up clutch. Mechanical Engineering and Automation, 2015, 6: 21-23. (in Chinese)

[23] N S Cheng. Principle and design of automotive metal continuously variable transmission-CVT. Beijing: China Machine Press, 2008: 166-167. (in Chinese)

[24] Z S Yu. Automotive theories. 5th Edition. Beijing: China Machine Press, 2009: 7-19. (in Chinese)

[25] T J Fu. Study on intelligent control of metal pushing V-belt type CVT. Changchun: Jilin University, 2004. (in Chinese)

[26] Z P Yang. Cruise software using vehicle power and fuel economy simulation analysis. Automobile Applied Technology, 2015(1): 107-109. (in Chinese)

[27] P Schoeggl, W Kriegler, E Bogner. Virtual optimization of vehicle and powertrain parameters with consideration of human factors. 2005 SAE World Congress, Detroit, Michigan, April 11-14, 2005

[28] M Andre. Driving cycles development: characterization of the methods. SAE International Spring Fuels and Lubricants Meeting, Dearborn, Michigan, May 6-8, 1996.

[29] J W Zhang, M L Li, G H Ai, et al. A study on the features of existing typical vehicle driving cycles. Automotive Engineering, 2005, 27(2): 220-224. (in (hinese)

[30] F X Zhang. Study on driving cycles of city vehicle. Wuhan: Wuhan University of Technology, 2005. (in Chinese)

[31] T Ma. Research on test method of hybrid electric vehicle motor based on driving cycle. Dalian: Dalian University of Technology, 2011. (in Chinese)

[32] General Administration of Quality Supervision, Inspection and Quarantine of the People's Republic of China; Standardization Administration of the People's Republic of China. GB/T 12545.1 - 2008. Measurement methods of fuel consumption for automobiles-Part 1: Measurement methods of fuel consumption for passenger cars. Beijing: China Standard Publishing House, 2009. (in Chinese) 